\title{
Performance and Carcass Characteristics of Broilers Under Diets Supplemented with Whole Grains
}

\author{
N.K. Sharma ${ }^{1}$, M. Sapkota ${ }^{1}$, R. Sah ${ }^{1}$, M.P. Sharma ${ }^{1}$, D. Creswell ${ }^{2}$ and N. Sharma ${ }^{3}$ \\ ${ }^{1}$ Institute of Agriculture and Animal Science (IAAS) \\ Tribhuvan University (TU), Rampur, Chitwan \\ ${ }^{2}$ Creswell Nutrition, Australia \\ ${ }^{3}$ Himalayan College of Agricultural Science and Technology \\ Purbanchal University, Gatthaghar, Bhaktapur \\ email:vet.nisha@gmail.com
}

\begin{abstract}
This study was conducted at the Institute of Agriculture and Animal Science (IAAS), Rampur, Chitwan with the objective to study the effects of mixing starter diet with whole grains on the performance and carcass characteristics of broilers. The control group (T1) was fed only with the commercial starter and grower diets throughout the experimental period. Other treatment groups, T2, T3, and T4 received commercial starter diets supplemented with whole wheat, cracked maize and bajra pearl millet (Pennisetum glaucam) respectively from day 6 . At 37 days, cumulative feed intakes $(\mathrm{FI})$ were significantly lower $(\mathrm{P}<0.01)$ for all the whole grain treated groups, the lowest FI being noted in T2 followed by T4 and T3. Cumulative body weights at 37 days were considerably poorer in the 3 whole grain treatments. Feed conversion ratio in T3 and T4 were equal to T1, at 1.70 whereas T2 FCR was 13 points higher than T1. Lower carcass yield and breast yield $(\mathrm{P}<0.05)$ were noted in whole grain diets except $\mathrm{T} 3$, which had similar figures to that of control. Whole grains produced a larger gizzards $(\mathrm{P}<0.01)$. Economic analysis favoured cracked maize and whole bajra treatments, each generating a net profit of NRs. 12.3/bird and NRs. 6.48/bird respectively. This study clearly demonstrated that these whole grains could be successfully fed to broilers in a method of diluting a starter diet. But more research is needed with higher nutrient density starter diets with some adjustments in whole grain dilution to develop an efficient method of whole grain feeding that gives at least equal weights, better FCR, and lower feed costs.
\end{abstract}

Key words: carcass, FCR, profit

\section{Introduction}

Broiler chickens share around $81 \%$ of the total poultry population in Nepal (MoAC 2011). These are also the major meat type birds in Nepal. Due to low initial investments and quick return, easy access to commercial feeds, and consumer's preference to broilers meat, broiler farming is becoming popular in Nepal. Feed represents the major cost of broiler production, constituting more than $70 \%$ of the total. Feed restrictions, diet dilution and semi or free-choice feeding are some of the dietary manipulations that have been tried in the past to reduce the feed costs and optimize growth rate and feed efficiency, but more recently the focus is on the utilization of whole grains in the ration (Yasar 2003).

Grinding of whole grains for broiler feeds constitutes the second greatest energy expenditure after pelleting and contributing to higher feed costs (Reece et al. 1985). Thus, any reduction in energy consumption from grinding could significantly lower feed cost. Kiiskinen (1996) reported that whole grain dilution of a starter feed is suitable for broiler production during the growing period. Some of these trials conducted with whole wheat dilution showed improved feed conversion ratio (FCR), and lower mortality, plus some 
carcass improvements. Chickens possess the ability to efficiently process and digest whole grains (Sturkie 1965), primarily due to significant increase in gizzard size, needed to grind the whole grains before passing down to the small intestine (Rose et al. 1986). The main advantages of whole wheat feeding for broilers are reduced feed costs due to reduced handling and processing costs of the feed (Svihus et al. 2004b), improved gut health (Gabriel et al. 2003, Bjerrum et al. 2005) and improved nutrient digestibility and apparent metabolizable energy (AME) (Preston et al. 2000, Hetland et al. 2002).

Svihus (2010) mentioned overconsumption of feed in modern broiler which may be reduced by providing them with more structural diet. There are a number of ways of providing a more structural diet, but the best and most economic appeared to be providing some grains in unground form, together with a pelleted feed. Petersen (1997) suggested that broiler chickens could grow optimally with whole wheat feeding with which whole grain can be included in broiler diet at the rate of $5 \%$ from $7^{\text {th }}$ day without any adjustment on the nutrient composition of diet, and then increased by an appropriate quantity for every 10 days to reach a 35\% inclusion at 42 day.

Numerous work that has been done earlier used whole grains in the feeds as a replacement for the existing cereal fraction. Very little work has been done to establish the effects of simple dilution of a single broiler feed with increasing quantities of whole grains. Cadogan and Creswell (2011) reported that a high amino acid density starter diet, when diluted with increasing quantities of either whole wheat or corn are able to meet the nutritional requirements of the broiler chicken on a daily basis.

Wheat, maize or bajra costs 50 percent less than a complete broiler feed. Dilution of broiler feed with either of these grains will decrease overall feed costs. The practical implication is that if the birds fed whole grains perform at least same as those fed complete diets, then the economics will favour whole grain feeding. In an effort to develop a good method of feeding whole grains for economic advantage, a trial was conducted in broilers. This trial tested three whole grains viz. wheat, maize and bajra with incremental dilution in broiler starter feed to study the performance and carcass characteristics of broilers.

\section{Methodology}

This study was conducted in 2012 at the Institute of Agriculture and Animal Science (IAAS) livestock farm, Rampur Chitwan. Five hundred and twenty straight run day old unsexed Cobb 500 broiler chicks were brooded in an electric brooder house for the first five days. At day 6, four hundred and eighty chicks were randomly sampled from the brooder house and divided equally into four treatment groups, each consisting of 120 chicks. Each treatment was replicated 6 times with each replicate/pen consisting of 20 chicks. The birds were reared in deep litter system made up of rice husk. Each pen was provided with equal sized feeder and drinker. Feed and water were provided ad libitum. The feed was manufactured in crumbled form by Probiotech Industries Pvt. Limited (Nimbus), Nepal. Maize, wheat and bajra with crude protein (CP) 7.6\%, 10.9\% and 9.8\% were used as whole grains.

Table 1. Feeding program of whole grains in various treatments

\begin{tabular}{|c|c|c|c|c|}
\hline \multicolumn{5}{|c|}{ Treatments $^{1}$} \\
\hline Periods & T1 & T2 & T3 & T4 \\
\hline $0-5 \mathrm{~d}$ & $100 \%$ starter & $100 \%$ starter & $100 \%$ starter & $100 \%$ starter \\
\hline $6-10 \mathrm{~d}$ & $100 \%$ starter & $95 \%$ starter $+5 \%$ wheat & $95 \%$ starter $+5 \%$ maize & $95 \%$ starter $+5 \%$ bajra \\
\hline $11-15 d$ & 100 \% starter & $90 \%$ starter $+10 \%$ wheat & $90 \%$ starter $+10 \%$ maize & $90 \%$ starter $+10 \%$ bajra \\
\hline $16-20 \mathrm{~d}$ & $100 \%$ grower & $85 \%$ starter $+15 \%$ wheat & $85 \%$ starter $+15 \%$ maize & $85 \%$ starter $+15 \%$ bajra \\
\hline $21-25 d$ & $100 \%$ grower & $80 \%$ starter $+20 \%$ wheat & $80 \%$ starter $+20 \%$ maize & $80 \%$ starter $+20 \%$ bajra \\
\hline $26-30 \mathrm{~d}$ & 100 \% grower & $75 \%$ starter $+25 \%$ wheat & $75 \%$ starter $+25 \%$ maize & $75 \%$ starter $+25 \%$ bajra \\
\hline $31-37 \mathrm{~d}$ & $100 \%$ grower & $70 \%$ starter $+30 \%$ wheat & $70 \%$ starter $+30 \%$ maize & $70 \%$ starter $+30 \%$ bajra \\
\hline
\end{tabular}

${ }^{1}$ T1 represents undiluted diet (control group); T2, T3 and T4 represent diets diluted with different levels of whole wheat, maize and bajra respectively. 
The four dietary treatments were: $\mathrm{T} 1$ : Starter crumble + grower crumble changing to grower at 16 days of age; T2: starter crumble plus whole wheat; T3: starter crumble plus cracked maize; and T4: starter crumble plus whole bajra. The percentage of whole grain dilution in starter feed in various treatments is shown in Table 1.

Treatment birds received whole grains, starting with $5 \%$ dilution from day 6 , and increasing the quantities every 5 days to end up with 30\% dilution from day 3137 (Table 1). Mixing was done manually on farm and all these diet mixtures were provided in a single feeder per pen. Feed intake and weight gain were measured on every $5^{\text {th }}$ day. Any leftovers at the end of every $5^{\text {th }}$ day were not removed from the feeder, but weighed, and the new mixture was added on that. Electronic balance was used to measure the weight gain of the birds. All twenty birds in each pen were weighed at a time and an average was taken to calculate weight of a single bird per pen. The composition of starter and grower diets and their nutritional analysis are presented in Table 2.

Table 2. Composition of starter and grower diets, based on maize, wheat, broken rice, soybean meal and soy oil

\begin{tabular}{l|c|c}
\hline Nutrients & Starter & Grower \\
\hline ME (Kcal/kg) & 2980 & 2980 \\
Crude protein \% & 22.36 & 20.97 \\
Calcium \% & 1.01 & 0.92 \\
Total Phosphorous \% & 0.73 & 0.66 \\
SID, \% & & \\
Lysine & 1.20 & 1.10 \\
Methionine & 0.44 & 0.42 \\
M+C & 0.86 & 0.82 \\
Tryptophan & 0.19 & 0.19 \\
Threonine & 0.78 & 0.75 \\
Arginine & 1.26 & 1.19 \\
Isoleucine & 0.80 & 0.76 \\
Valine & 0.92 & 0.88 \\
\hline
\end{tabular}

The birds were harvested after 37 days for carcass evaluation (carcass yield, breast yield, thigh yield, drumstick, gizzard, intestine, back, wings and liver). Two birds from each pen, i.e., 12 birds from each treatment were sacrificed after 37 days to study the carcass characteristics. These birds were fasted for 12 hours but provided with ad libitum water before slaughter.

The experiment was conducted in a completely randomized design. For significance test, one way analysis of variance was performed. Treatment means were compared by least significant difference $(\mathrm{p}<0.05)$ using M- Stat C Version 1.3.

\section{Results and Discussion \\ Performance of broilers under different dietary treatments}

The chicks could easily consume crumble starter and whole grain mixtures from day 6 onwards without selection and the mixture was seen as homogenous throughout the trial. At 37 days, cumulative feed intakes (FI) were significantly lower $(\mathrm{P}<0.01)$ for all whole grain treated groups (Fig. 1). FI decreased by $7.52 \%, 4.94 \%$ and $5.87 \%$ in T2, T3 and T4 respectively as compared to the control group. Average whole grain intake at day 37 was $21 \%$ of the total feed intake.

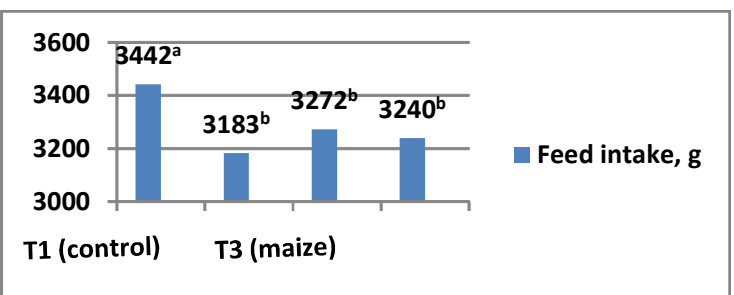

Fig. 1. Total feed consumption among all treatments at day 37

Cumulative body weights at 37 days were considerably poorer in the 3 whole grain treatments (Table 3). Feed conversion ratio in $\mathrm{T} 3$ and $\mathrm{T} 4$ were equal to $\mathrm{T} 1$, at 1.70 whereas T2 FCR was 13 points higher than T1 (Fig. 2). Better FCR was seen from cracked maize and bajra during finishing period which made overall FCR of these treatments equal to that of control.

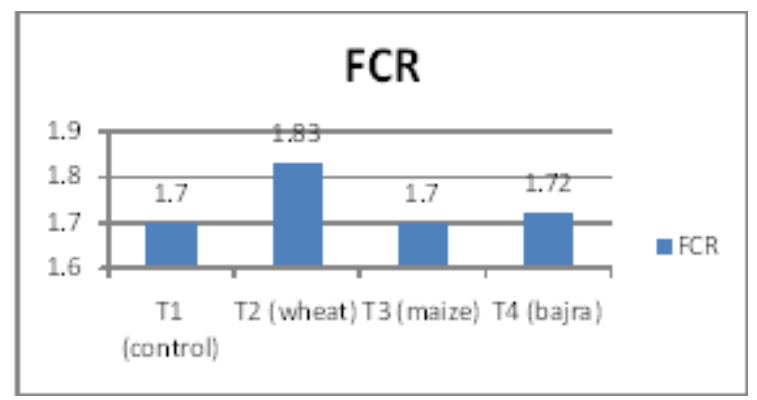

Fig. 2. Corrected feed conversion ratio for all treatments at day 37 
Mortality rate was below 3\% in T1, T3 and T4 whereas T2 group had mortality rate of $7.5 \%$. Birds that died in the control group were found dead during the finishing period with ascites symptoms whereas most of the birds that died in whole grain treated groups were showing symptoms of skeletal defect and lameness in early stages of their life.

Table 3. Effects of whole grain treatments on broiler performance 1-37 days

\begin{tabular}{|c|c|c|c|c|}
\hline Treatments & LW, grams & Feed,grams & F CR & Mortalify, number \\
\hline T1 & $2031^{2}$ & $3442^{\mathrm{a}}$ & $1.70^{6}$ & 3 \\
\hline $\mathrm{T} 2$ & $1739^{\circ}$ & $3183^{b}$ & $1.83^{\mathrm{a}}$ & 9 \\
\hline T3 & $1926^{\mathrm{b}}$ & $3272^{b}$ & $1.70^{\mathrm{b}}$ & 3 \\
\hline T4 & $1878^{b}$ & $3240^{b}$ & $1.72^{\mathrm{b}}$ & 3 \\
\hline Probability & $* *$ & $* *$ & $* *$ & \\
\hline F-value & 25.987 & 9.638 & 6.733 & \\
\hline $\operatorname{LSD}_{(p<0.05)}$ & 69.98 & 105.8 & 0.07617 & \\
\hline $\mathrm{CV} \%$ & 3.07 & 2.68 & 3.48 & \\
\hline SEMI & 24.48 & 26.15 & 0.02 & \\
\hline
\end{tabular}

T1 represents undiluted diet (control group); T2, T3 and T4 represent diets diluted with different levels of whole wheat, maize and bajra respectively.

a,b,c Means within a row with different superscripts are significantly different, $\mathrm{P}<0.05$.

${ }^{*}$ Indicates significant $(\mathrm{P}<0.05)$

${ }^{* *}$ Indicates highly significant $(\mathrm{P}<0.01)$

\section{Carcass characteristics of broilers under different dietary treatments}

Lower carcass yield and breast yield were noted in whole grain treated diets except cracked maize (Table 4). Whole grains produced a significantly larger gizzard $(\mathrm{P}<0.01)$. This represents more functional gizzard. Gizzard yield was increased by $42.42 \%$, 34.85\% and $35.1 \%$ with whole wheat, cracked maize and pearl millet respectively.

Table 4. Carcass characteristics of broiler chickens fed with diets supplemented with different levels of whole grains

\begin{tabular}{|c|c|c|c|c|c|c|}
\hline \multirow{2}{*}{$\begin{array}{l}\text { Items } \\
\text { (yield as } \% \text { of live weight) }\end{array}$} & \multicolumn{6}{|c|}{ T reatments } \\
\hline & T 1 & T2 & T3 & T4 & CV\% & SEM \\
\hline $\begin{array}{l}\text { Carcass" } \\
\text { Breast rouscle with bone } \\
\text { Abdominal fat } \\
\text { Gizzand " } \\
\text { Irtestine }\end{array}$ & $\begin{array}{l}75.04^{4} \\
26.74^{4} \\
0.9317^{4 b} \\
1.317^{b} \\
5.372^{4 b}\end{array}$ & $\begin{array}{l}72.69^{b} \\
24.13^{6} \\
0.9617^{\star b} \\
1.882^{\wedge} \\
5.987^{\wedge}\end{array}$ & $\begin{array}{l}75.43^{\mathrm{n}} \\
26.04^{\mathrm{Ab}} \\
1.062^{\mathrm{a}} \\
1.780^{\mathrm{a}} \\
4.735^{\mathrm{b}} \\
\end{array}$ & $\begin{array}{l}73.54^{b} \\
24.88^{\mathrm{k}} \\
0.7567^{\mathrm{b}} \\
1.783^{\mathrm{n}} \\
5.420^{\mathrm{Ab}}\end{array}$ & $\begin{array}{l}157 \\
456 \\
23.47 \\
953 \\
12.39 \\
\end{array}$ & $\begin{array}{l}0.32 \\
0.31 \\
0.05 \\
0.06 \\
0.16\end{array}$ \\
\hline
\end{tabular}

${ }^{1} \mathrm{~T} 1$ represents undiluted diet (control group); T2, T3 and T4 represent diets diluted with different levels of whole wheat, maize and bajra respectively.

a,b,c Means within a row with different superscripts are significantly different, $\mathrm{P}<0.05$.

*Indicates significant $(\mathrm{P}<0.05)$

** Indicates highly significant $(\mathrm{P}<0.01)$

Cracked maize produced smaller intestine $(\mathrm{P}<0.05)$ as compared to others. This may represent a more efficient intestine, which would use less energy for maintenance. There is no significant difference $(\mathrm{P}>0.05)$ in yield of drumstick, wings, leg piece and back with all the four treatments. Abdominal fat yield was highest in $\mathrm{T} 4(\mathrm{P}<0.05)$ and similar in other treatments.

\section{Economic analysis}

Economic analysis favoured cracked maize and whole bajra treatments. Cracked maize and whole bajra generated net profits of NRs. 12.3/bird and NRs. 6.48/ bird respectively (Table 5). 
N. K. Sharma et al./Performance and Carcass characteristics.....

Table 5. Economics of broiler production through whole grain use

\begin{tabular}{|c|c|c|c|c|}
\hline \multirow[t]{2}{*}{ Feed Type } & \multicolumn{4}{|c|}{ Aver age feed consumed/bird(in kg) and cost involved } \\
\hline & $\mathrm{TO}$ & T1 & $\mathrm{T} 2$ & T3 \\
\hline $\begin{array}{l}\text { Broiler starter } \\
\text { Cost@ NRs. } 52.55 / \mathrm{kg} \\
\text { Broiler grower } \\
\text { Cost @ NRs. } 51.30 / \mathrm{kg} \\
\text { Whole Wheat } \\
\text { Cost@ NRs. } 20 / \mathrm{kg} \\
\text { Cracked maize } \\
\text { Cost (including cracking) }(N R s .20 / \mathrm{kg} \\
\text { Whole Baira } \\
\text { Cost@ NRs. } 19 / \mathrm{kg} \\
\text { Total feed consumed per bird(kg) } \\
\text { Feed cost/birdin NRs. (x) }\end{array}$ & $\begin{array}{l}0.57 \\
29.95 \\
2.87 \\
147.23 \\
0 \\
0 \\
0 \\
0 \\
0 \\
0 \\
3.44 \\
177.18\end{array}$ & $\begin{array}{l}2.52 \\
132.43 \\
0 \\
0 \\
0.66 \\
13.2 \\
0 \\
0 \\
0 \\
0 \\
3.18 \\
145.63\end{array}$ & $\begin{array}{l}2.58 \\
135.58 \\
0 \\
0 \\
0 \\
0 \\
0.69 \\
13.8 \\
0 \\
0 \\
3.27 \\
149.38\end{array}$ & $\begin{array}{l}2.56 \\
134.53 \\
0 \\
0 \\
0 \\
0 \\
0 \\
0 \\
0.68 \\
12.92 \\
3.24 \\
147.45\end{array}$ \\
\hline $\begin{array}{l}\text { Avg live wt/bird (Kg) } \\
\text { Avg income per bird(d) Rs. } 155 / \mathrm{kg} \text { live wt (y) } \\
\text { Feed cost } / \mathrm{kg} \text { live wt. of bird (NRs.) }\end{array}$ & $\begin{array}{l}2.03 \\
314.65 \\
87.28\end{array}$ & $\begin{array}{l}1.74 \\
269.7 \\
83.70\end{array}$ & $\begin{array}{l}1.93 \\
299.15 \\
77.40\end{array}$ & $\begin{array}{l}1.88 \\
291.4 \\
78.43\end{array}$ \\
\hline $\begin{array}{l}\text { Return to farmer/ live bird in NRs. (y-x): cost of } \\
\text { chicks (NRs. } 50 / \text { chick) and other non-feed cost are } \\
\text { constant for all treatments and therefore not } \\
\text { included. }\end{array}$ & $\begin{array}{l}137.47 \\
x\end{array}$ & $\begin{array}{l}124.07 \\
x\end{array}$ & $\begin{array}{l}149.77 \\
\mathrm{x}\end{array}$ & $\begin{array}{l}143.95 \\
\mathrm{x}\end{array}$ \\
\hline
\end{tabular}

${ }^{\mathrm{x}}$ Represents constant cost

NRs.- Nepali Rupees

In terms of net return,

- Whole wheat: NRs. (124.07-137.47)= loss of NRs. 13.40/bird

- $\quad$ Cracked maize: NRs. (149.77-137.47)= gain of NRs. 12.3/bird

- Whole bajra: NRs. (143.95-137.47)= gain of NRs. 6.48/bird

Several researches have been conducted with a feeding program using whole grains, especially whole wheat, barley or maize. They were generally added to starter, grower or finisher diets at certain levels or simply to a starter diets changing the diet specification on a certain interval. These researches have generally shown improved FCR, lower mortality, plus some carcass improvements and economic advantage.

This is the first time whole pearl millet (bajra) has been tested. This trial tested three whole grains viz. whole wheat, cracked maize and pearl millet inclusions in starter crumble (dig. lysine $1.20 \%$ ) to see the performance and carcass characteristics of broilers. Treatment birds received whole grains, starting with $5 \%$ dilution from day 6 , and increasing the quantities every 5 days to end up with $30 \%$ dilution from day 3137. Chickens were able to pick whole grains comfortably from day 6 and there were no wastage of

grains in the litter. Feed intake was significantly reduced in whole grain added diets; the lowest feed intake being noted in whole wheat diet followed by bajra and cracked maize diets. Cadogan and Cresswell (2011) found similar decrease in feed intake when the birds were fed starter pellets plus whole wheat. The reduced feed consumptions were from 100-400 g/bird. This finding supported the findings of Svihus (2010) who mentioned that the use of whole grains in pelleted feed could reduce the overconsumption behaviour of ad libitum fed modern broilers.

All three whole grain treatments had poorer growth as compared with the control. The cracked maize treatment, however, performed almost equal to that of the control, being 105g lighter and with equal FCR (1.70). It is known that the number of pecks to consume a given amount of feed is reduced when particle size increases (Jensen et al. 1962). So, after adequate gizzard development, birds require lower energy inputs to consume coarser particles. Cracked maize produced smaller intestine $(\mathrm{P}<0.05)$ as compared to others. This may represent a more efficient intestine, which would use less energy for maintenance. This may partly explain the reason behind good performance through the use of cracked maize in feed. Bajra treatment performed equally better in terms of FCR (1.72). It is 
suggested that the lower feed consumption was responsible for the slower growth of the whole grain treated birds. Some earlier reports also indicated decreased growth rate of broilers on addition of whole wheat to broiler diets (Munt et al. 1995, Uddin et al. 1996).

Carcass parameters were poorer with the whole grain treatments, but again the cracked maize was very similar to the control. Whole grains produced a significantly larger gizzard $(\mathrm{P}<0.01)$. This represents more functional gizzard. Increase in gizzard size through whole wheat treatment was also noted by Preston et al. (2000), Bennet et al. (2002), Plavnik et al. (2002), Gabriel et al. (2003), Wu et al. (2004), Wu and Ravindran (2004), Bjerrum et al. (2005), Ravindran et al. (2006), Amerah and Ravindran (2008), Gabriel et al. (2008), Biggs and Parsons (2009) and Svihus (2010). A large, well-developed gizzard improves gut motility (Ferket 2000) through increasing the levels of cholecystokinin release (Svihus et al. 2004) which stimulates the secretion of pancreatic enzymes and the gastro-duodenal reflexes (Duke 1992, Li \& Owyang 1993). Coarse particles may slow the passage of digesta through the gizzard (Nir et al. 1994a), increasing the exposure time of nutrients to digestive enzymes, which in turn, may improve energy utilization and nutrient digestibility (Carre 2000).

Poor performance and carcass yield with whole grain treatments may be due to low amino acids/protein in starter diets and decreased feed consumptions. Despite some poorer performance with whole grain treatments, the economics still favoured the use of cracked maize and bajra; cracked maize generating a net profit of NRs. 12.3/bird and bajra producing a net gain of NRs. 6.48/ bird.

This trial demonstrated that these whole grains could be successfully fed to broilers in a method of diluting a starter diet. However, some further refinements of the program is necessary before we can be confident that whole grain feeding programs will offer performance levels at least equal to a standard crumble/pellet program. Most likely this will require use of a higher nutrient density starter diet.

\section{Acknowledgements}

We would like to thank Probiotech Industries Pvt. Limited (Nimbus) and Fewa International Company Pvt. Ltd for partially funding for this research.

\section{References}

Amerah, A.M. and V. Ravindran. 2008. Influence of method of whole- wheat feeding on the performance, digestive tract development and carcass traits of broiler chickens. Animal Feed Science and Technology 147:326-339.

Bennet, C.D., H.L. Classen and C. Riddell. 2002. Feeding broiler chicken wheat and barley diets containing whole, ground and pelleted grain. Canadian Journal of Animal Science 75: 611-614.

Bjerrum, L., K. Pedersen and R.M. Engberg. 2005. The influence of whole wheat feeding on salmonella infection and gut flora composition in broilers. Avian Disease 49:915.

Biggs, P. and C.M. Parsons. 2009. The effects of whole grains on nutrient digestibilities, growth performance, and caecal short-chain fatty acid concentrations in young chicks fed ground corn-soybean meal diets. Poultry Science 88:18931905.

Cadogan, D. and D. Creswell. 2011. Whole grain feeding reduces diet cost and improves feed efficiency. Unpublished Paper. Feedworks. Australia.

Carre, B. 2000. Effets de la taille des particules alimentaires sur les processus digestifs chez les oiseaux d'elevage. INRA Productions Animales 13:131-136.

Duke, G.E. 1992. Recent studies on regulation of gastric motility in turkeys. Poultry Science 71: 1-8.

Ferket, P. 2000. Feeding whole grains to poultry improves gut health. Feedstuffs (USA). September 4: 12-14.

Gabriel, I., M. Mallet and M. Leconte. 2003. Differences in the digestive tract characteristics of broiler chickens fed on complete pelleted diet or on whole wheat added to pelleted protein concentrate. Brit. Poultry Sci. 44:283290.

Gabriel, I., S. Mallet., M. Leconte., A. Travel and J.P. Lalles. 2008. Effects of whole wheat feeding on the development of the digestive tract of broiler chickens. Animal Feed Science and Technology 142:144-162.

Hetland, H., B. Svihus and V. Olaisen. 2002. Effect of feeding whole cereals on performance, starch digestibility and duodenal particle size distribution in broilers chickens. British Poultry Science 43:416-423.

Jensen, L.S., H. Merill., C.V. Reddy and J. McGinnis. 1962. Observation on eating patterns and rate of passage of birds fed pelleted and unpelleted diets. Poultry Science 41:1414-1419.

Kiiskinen, T. 1996. Feeding whole grain with pelleted diets to growing broiler chickens. Agricultural and Feed Science in Finland 5:167-175.

Li, Y. and C. Owyang. 1993. Vagal afferent pathway mediates physiological action of cholecystokinin on pancreaticenzyme secretion. Journal of Clinical Investigation 92: 418-424.

MoAC. 2011. Statistical information on Nepalese agriculture. Government of Nepal. Agriculture Information and Communication Centre. Ministry of Agriculture and Cooperative. Hariharbhawan, Lalitpur. 


\section{N. K. Sharma et al./ Performance and Carcass characteristics.....}

Munt, R.H.C., J.G. Dingle and M.G. Sumpa. 1995. Growth, carcass composition and profitability of meat chickens given pellets, mash or free-choice diet. British Poultry Science 36:277-284.

Nir, I., R. Hillel., G. Shefet and Z. Nitsan. 1994a. Effect of grain particle size on performance. 2. Grain texture interactions. Poultry Science. 73:781-791.

Petersen, C. B. 1997. Practical application of whole grain feeding. In: Proceedings of the $11^{\text {th }}$ European Symposium on Poultry Nutrition. World's Poultry Science Association, Faaborg, Denmark, pp. 6-15.

Plavnik, I., B. Macovsky and D. Sklan. 2002. Effects of feeding whole wheat on performance of broiler chickens. Animal Feed Science and Technology 96:229-236.

Preston, C.M., K.J. McCracken and A. McAllister. 2000 Effect of diet form and enzyme supplementation on growth, efficiency and energy utilisation of wheat-based diets for broilers. British Poultry Science 41:324-331.

Ravindran,V., Y.B. Wu., D.G. Thomas and P.C.H. Morel. 2006. Influence of whole wheat feeding on the development of gastrointestinal tract and performance of broiler chickens. Aust. J. Agric. Res. 57: 21-26.

Reece, F.N., B.D. Lott and J.W. Deaton. 1985. The effects of feedform, grinding method, energy level and gender on broiler performance in a moderate (21 C) environment. Poult. Sci. 64:1834-1839.

Rose, S.P., A. Burnetti and R.A. Elmajeed. 1986. Factors affecting the diet selection of choice fed broilers. British Poultry Science 27:215-224.

Sturkie, P.D. 1965. Avian physiology. London: Balliere, Tindall and Cassell.
Svihus, B., K.H. Klovstad., V. Perez., O. Zimonja., S. Sahlstrom., R.B. Schuller., W.K. Jeksrud and E. Prestlokken. 2004. Physical and nutritional effects of pelleting of broiler chicken diets made from wheat ground to different coarsenesses by the use of roller mill and hammer mill. Animal Feed Science and Technology 117:218-293.

Svihus, B. 2010. Challenging current poultry feeding dogmas by feed intake restriction and the use of coarse feed ingredients. Proceedings Australian Poultry Science Symposium 21: 9-15.

Uddin, M.S., S.P. Rose., T.A. Hiscock and S. Bonnet. 1996. A comparison of the energy availability for chickens of ground and whole grain samples of two wheat varieties. British Poultry Science 37:347-357.

Wu, Y.B. and V. Ravindran. 2004. Influence of whole wheat inclusion and xylanase supplementation on the performance, digestive tract measurements and carcass characteristics of broiler chickens. Anim. Feed Sci. Technol. 116:129-139.

Wu, Y.B., V. Ravindran., D.G. Thomas., M.J. Birtles and W.H. Hendriks. 2004. Influence of method of whole wheat inclusion and xylanase supplementation on the performance, apparent metabolisable energy, digestive tract measurements and gut morphology of broilers. $\mathrm{Br}$. Poult. Sci 45:385-394.

Yasar, S. 2003. Performance of broiler chickens on commercial diets mixed with whole or ground wheat of different varieties. International Journal of Poultry Science 2(1):62-70. 
Nepal Journal of Science and Technology Vol. 13, No. 2 (2012) 21-28 